\title{
Distribution, activation and tryptase/chymase phenotype of mast cells in the rheumatoid lesion
}

\author{
Lynne C Tetlow, David E Woolley
}

\begin{abstract}
Objective-To determine the distribution, activation, and tryptase/chymase phenotype of mast cells (MCs) in the rheumatoid lesion.

Methods-MC tryptase and chymase were studied by immunohistochemistry using monoclonal antibodies and examination by brightfield, interference, and fluorescent microscopy. Thirty four specimens of cartilage-pannus junction and 26 specimens of rheumatoid synovium, all derived from knee surgery, were examined.
\end{abstract}

Results-MCs were identified in all specimens examined, but their distribution and local concentrations varied, both within and between specimens. As a proportion of total synovial cells, there were more MCs in fibrous synovial tissues than in those with active inflammatory cell infiltrations; MCs usually showed a peripheral distribution around lymphocytic/mononuclear cell infiltrations. Most cartilage-pannus specimens demonstrated local concentrations of $\mathrm{MCs}$ at, or close to, sites of cartilage erosion, a significant proportion of which showed extracellular tryptase indicative of MC degranulation. MC degranulation was often associated with localised oedema and disruption of the stromal matrix. Two MC phenotypes were identified: one population contained tryptase alone $\left(\mathbf{M C}_{\mathrm{T}}\right)$ whilst another contained both tryptase and chymase $\left(\mathrm{MC}_{\mathrm{TC}}\right)$. The ratio $\mathbf{M C}_{\mathrm{T}}: \mathbf{M C}_{\mathrm{TC}}$ approximated 8:1.

Conclusions-This histological study demonstrated that local concentrations of MCs and their activation/degranulation are commonly observed in the rheumatoid lesion, and especially at sites of cartilage erosion. Such observations add weight to the concept that MCs contribute to the processes of inflammation, matrix degradation and tissue remodelling.

(Ann Rheum Dis 1995; 54: 549-555)

Extensive proteolytic degradation of articular cartilage is a characteristic feature of joint destruction in rheumatoid arthritis. This irreversible process is commonly associated with invasive hypertrophied synovium, the type of cells observed at sites of erosion showing marked heterogeneity. ${ }^{1}$ Histological studies have reported mast cell (MC) hyperplasia in rheumatoid synovia ${ }^{2-5}$ and their presence at sites of cartilage erosion. ${ }^{6}$ The $M C$ is now considered to play a pivotal role in a variety of biological responses, including allergic reactions, fibrosis, angiogenesis, wound healing, inflammation, and tissue remodelling..$^{7-9}$ As MCs contain a variety of potent mediators such as histamine, heparin, proteinases, leukotrienes, and multifunctional cytokines, ${ }^{7}{ }^{10}$ it is probable that the MC participates in the processes of inflammation, matrix degradation and tissue remodelling, although the extent of its contribution and its precise functional role(s) remain to be defined.

Earlier histological studies of MCs in rheumatoid synovia have usually used metachromatic staining of the heparincontaining MC granules with conventional stains such as toluidine blue, Giemsa or Alcian blue. $^{3511}$ However, these methods give little indication of MC activation/degranulation and are inferior to the more sensitive immunological techniques using antibodies to MC histamine ${ }^{12}$ or the specific MC proteinases, tryptase and chymase. ${ }^{13}$ As both these enzymes are components of MC granules, their tissue distribution provides an assessment of MCs in both non-activated and degranulated states.

Variation in proteinase content is a major feature of MC heterogeneity. ${ }^{14}{ }^{15}$ In humans, tryptase is the dominant enzyme of most MCs found in mucosal tissue of the gut and lungs, but MCs containing both tryptase and chymase have been reported in most tissues, especially in skin and intestinal submucosa. ${ }^{79}$ Previous studies of MCs in rheumatoid synovia indicated a homogeneous population with phenotypic and functional similarities. ${ }^{516}$ Using dual immunolocalisation studies to detect the MC enzymes tryptase and chymase, we report here the existence of two MC phenotypes in rheumatoid synovia, provide a detailed assessment of MC distribution and activation in the rheumatoid lesion, and demonstrate that MC activation/degranulation is commonly associated with localised oedema and stromal disruption.

\section{Materials and methods}

TISSUE SAMPLES

Specimens of cartilage-pannus junction and rheumatoid synovial tissue were obtained from 
34 patients (26 women and eight men, age range 46-79 years) with late stage classic rheumatoid arthritis undergoing arthroplasty of the knee. Joint tissues were transferred to the laboratory in Hanks's balanced salt solution (HBSS) and junctional specimens (cartilage with overlying synovial tissue) were carefully sampled. Although all surgical specimens showed extensive cartilage loss, with denuded bone a common feature, residual cartilage with overlying rheumatoid synovium was usually available for sampling and represented various stages of cartilage erosion from each joint. After one hour in Carnoy's fixative the specimens were conventionally embedded in paraffin wax and $5 \mu \mathrm{m}$ sections were cut, dewaxed and rehydrated, and examined for the presence of MC tryptase and MC chymase. In addition, rheumatoid synovial tissues not associated with cartilage or bone were obtained from 26 remedial synovectomies and similarly processed.

Because all these synovial specimens showed wide variations in tissue histology, including cellular composition and the amount of fibrous stroma, each specimen was classified by histological appearance to one of three groups, defined as 'cellular', 'fibrous', or 'cellular/ fibrous'. The quantification of MC distribution, avoiding major blood vessels, was evaluated in specimens of these three groups by examination (with a $\times 40$ objective) of eight fields of at least two slides per specimen, and calculated as a proportion of total cell numbers determined by haematoxylin counterstain.

IMMUNOLOCALISATION OF MC PROTEASES

Mouse monoclonal antibody to human MC tryptase (Chemicon International, London, UK) was diluted 1:300 in Tris-buffered saline, pH 7.6 (TBS) and applied to the tissue sections for two hours at $20^{\circ} \mathrm{C}$. After three 10 minute washes in TBS, the sections were exposed to alkaline phosphatase-conjugated goat antimouse antibody (Dako, UK) diluted 1:50 in TBS for one hour. After further washing the alkaline phosphatase was developed using New Fuchsin substrate as previously described. ${ }^{17}$

Mouse monoclonal antibody to human MC chymase (Chemicon International) was diluted 1:100 in TBS and applied to the sections for two hours at $20^{\circ} \mathrm{C}$, with subsequent procedures as described above for the localisation of tryptase.

TBS or normal mouse IgG (Dako) in concentrations similar to those of the primary antibodies were substituted for the primary antibody on control tissue sections of each specimen and consistently produced negative observations.

All tissue sections were lightly counterstained with Harris's haematoxylin to demonstrate nuclei (bluish-grey) and subsequently mounted in Histomount (Mensura Technology, Wigan, UK), examined, and photographed using a Zeiss photomicroscope III and Ektachrome 160 tungsten film.
DUAL IMMUNOLOCALISATION OF MC TRYPTASE AND CHYMASE

MC chymase was localised using the primary antibody described above but with fluorescein isothiocyanate(FITC)-conjugated rabbit antimouse IgG as the secondary antibody. The tissue sections were subsequently treated with an excess of normal mouse IgG to eliminate cross reactivity with the primary antibody to MC tryptase. The latter, conjugated directly to alkaline phosphatase (Chemicon International) was subsequently applied to the tissue sections and developed using Fast red substrate which fluoresces red under conventional ultraviolet illumination. The tissue sections were mounted in Immunomount (Shandon, UK), examined, and photographed using a Zeiss photomicroscope III with filter sets for FITC or Fast red.

\section{Results}

MC tryptase was shown to be an effective marker for synovial MCs and its extracellular distribution provided an assessment of MC activation/degranulation. All specimens of rheumatoid synovium showed the presence of MCs, but their distribution and local concentrations, both within and between specimens, were variable. Of the 34 specimens of cartilage-pannus junction examined, 25 showed evidence of MCs located at the cartilage-pannus interface. Seventeen of these showed evidence of MC activation as judged by extracellular tryptase close to sites of cartilage erosion (fig 1). Other specimens showed the presence of MCs at or near the junction, but without tryptase release. Of particular note was the observation that when MCs were observed at sites of cartilage erosion they usually represented a locally increased concentration compared with their distribution within the supporting synovium.

Concerns as to whether some observations of extracellular tryptase may have been artificially induced by the physical trauma of surgery and sampling were alleviated to some extent by observations showing local tryptase uptake by neighbouring synoviocytes surrounding activated MCs (fig $1 D$ ). Such observations are in accord with previous reports that both mononuclear phagocytes ${ }^{18}$ and fibroblasts ${ }^{19}$ effectively phagocytose extruded MC granules (and the tryptase component). In addition, most specimens demonstrated both intact and degranulated MCs within the same tissue section (fig $1 \mathrm{~A}, \mathrm{C})$, thereby providing some reassurance that $M C$ integrity was retained during sampling processes.

Throughout this study the histological heterogeneity of pannus tissue overlying cartilage was evident. It was possible to recognise three types of pannus tissue:

cellular, in which the tissue was predominantly comprised of cells such as fibroblasts, macrophages, and variable numbers of $T$ cells and plasma cells (figs $1 \mathrm{D}, 2 \mathrm{~F}, \mathrm{G}$ );

fibrous, in which the dominant component was stromal connective tissue, with relatively few fibroblasts and blood vessels (figs 1A, 2A); 

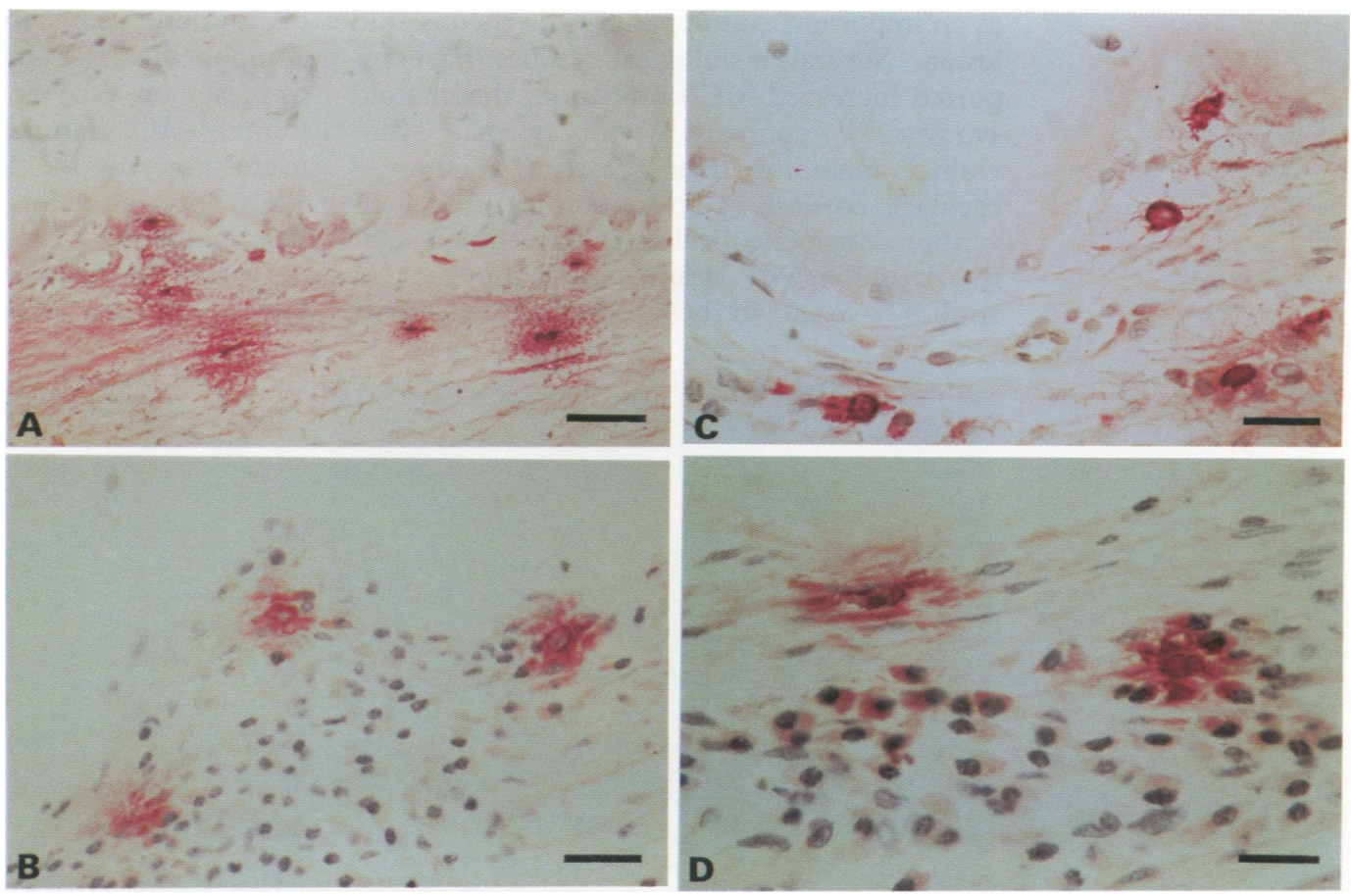

Figure 1 Immunolocalisation of mast cell (MC) tryptase at the rheumatoid lesion in knee joints of patients with classic seropositive rheumatoid arthritis. A: Photomicrograph demonstrating both intra- and extracellular MC tryptase at the cartilage-pannus junction. Note halos of immunoreactive tryptase indicative of MC degranulation and traces of tryptase staining on the cartilage at the interface with the synovial tissue. (Man, 65 years.) Horizontal bar represents $60 \mu \mathrm{m}$. B: Photomicrograph showing MC tryptase at the cartilage-pannus interface. Note close apposition of activated MCs to cartilage surface. (Woman, 64 years.) Bar, $35 \mu \mathrm{m}$. C: Photomicrograph showing both intact and activated MCs at the cartilage-pannus junction. Note extracellular staining of tryptase associated with connective tissue elements at sites of cartilage erosion. (Woman, 74 years.) Bar, $25 \mu \mathrm{m}$. D:Photomicrograph demonstrating two activated MCs as judged by extracellular tryptase at the cartilage-pannus junction. Note intracellular uptake of tryptase by adjacent synoviocytes. (Woman, 59 years.) Bar, $25 \mu \mathrm{m}$.

cellular/fibrous, in which different locations within the same specimen showed either cellular or fibrotic characteristics (fig $2 \mathrm{C}, \mathrm{E}$ ). MC numbers were evaluated for several specimens from each of these categories (table). MCs represented a significantly greater proportion of total cells in the fibrous (approximately $2 \cdot 8 \%$ ) than in the cellular (approximately $1 \cdot 18 \%$ ) type of synovial pannus. Synovial tissues with a prominent inflammatory cell component invariably demonstrated MCs located at the periphery of lymphocytic/mononuclear cell infiltrations (fig $2 \mathrm{E}, \mathrm{G}$ ), whereas in fibrous synovial specimens the MCs were usually distributed evenly throughout the tissue (fig 2A, B).

Occasionally; large numbers of MCs, many showing extracellular tryptase, were observed in discrete regions of pannus tissue. Two specimens in particular were heavily stained for extracellular tryptase throughout the tissue, and each demonstrated clear histological evidence for connective tissue disruption and lysis (fig 2G, H), as judged by Nomarski interference microscopy. Other specimens showing more localised MC activation were also commonly associated with tissue oedema and matrix disruption (fig $2 \mathrm{C}, \mathrm{D}$ ). In contrast, where intact MCs were observed the surrounding stroma was consistently well ordered (fig 2A, B).

MC heterogeneity, recognised by the differential content of MC tryptase and chymase, is an established feature of MC biology in which specific tissues usually illustrate one particular MC phenotype.
Immunolocalisation of $\mathrm{MC}$ chymase revealed positive staining for all the synovial specimens examined $(n=11)$. Evidence for chymasecontaining MCs at the rheumatoid lesion is shown in figure $3 \mathrm{~A}$, and a local concentration of similar MCs within rheumatoid synovial tissue is shown in figure 3B. However, the numbers of chymase-containing MCs were far fewer than those of MCs containing tryptase. Comparative studies using adjacent sections of synovial tissues stained for MC tryptase or chymase, respectively, demonstrated that although chymase-containing MCs were always observed, their proportion never exceeded $20 \%$ of the total MCs. These observations were subsequently extended using dual immunolocalisation of MC tryptase and chymase on the same tissue sections (fig 3C, D). These studies demonstrated and confirmed the existence of two distinct MC phenotypes in synovial tissues. The predominant MC type in all specimens contained tryptase $\left(\mathrm{MC}_{\mathrm{T}}\right)$, whereas a small proportion (range $5-18 \%$ ) of synovial MCs contained both chymase and tryptase $\left(\mathrm{MC}_{\mathrm{TC}}\right)$. No MC was in any of the specimens was observed to contain only chymase.

\section{Discussion}

Rheumatoid arthritis is a chronic inflammatory disease characterised by synovial hyperplasia and hypertrophy. Numerous reports have described specific cellular components of the inflamed synovial tissue, such as macrophages, $T$ lymphocytes, neutrophils, and fibroblasts, but only recently has the $\mathrm{MC}$ been recognised 
as an important component of the rheumatoid lesion. Several histological studies have reported increased $\mathrm{MC}$ numbers in rheumatoid synovia $^{2-511}$ compared with normal synovium, ${ }^{20}$ including their presence at sites of cartilage erosion. ${ }^{16}$ Those studies used conventional histochemical staining techniques for the basophilic MC granules, but more recent studies have shown these to lack the sensitivity of immunohistochemistry for specific MC components. ${ }^{12}{ }^{13}{ }^{15}$ Immunolocalisation of MC tryptase, an enzyme unique to virtually all human MC granules ${ }^{13} 15$ has proved most useful not only for the identification of intact MCs, but also for an assessment of MC degranulation.

During this histological study of rheumatoid knee specimens, we have noted wide variations
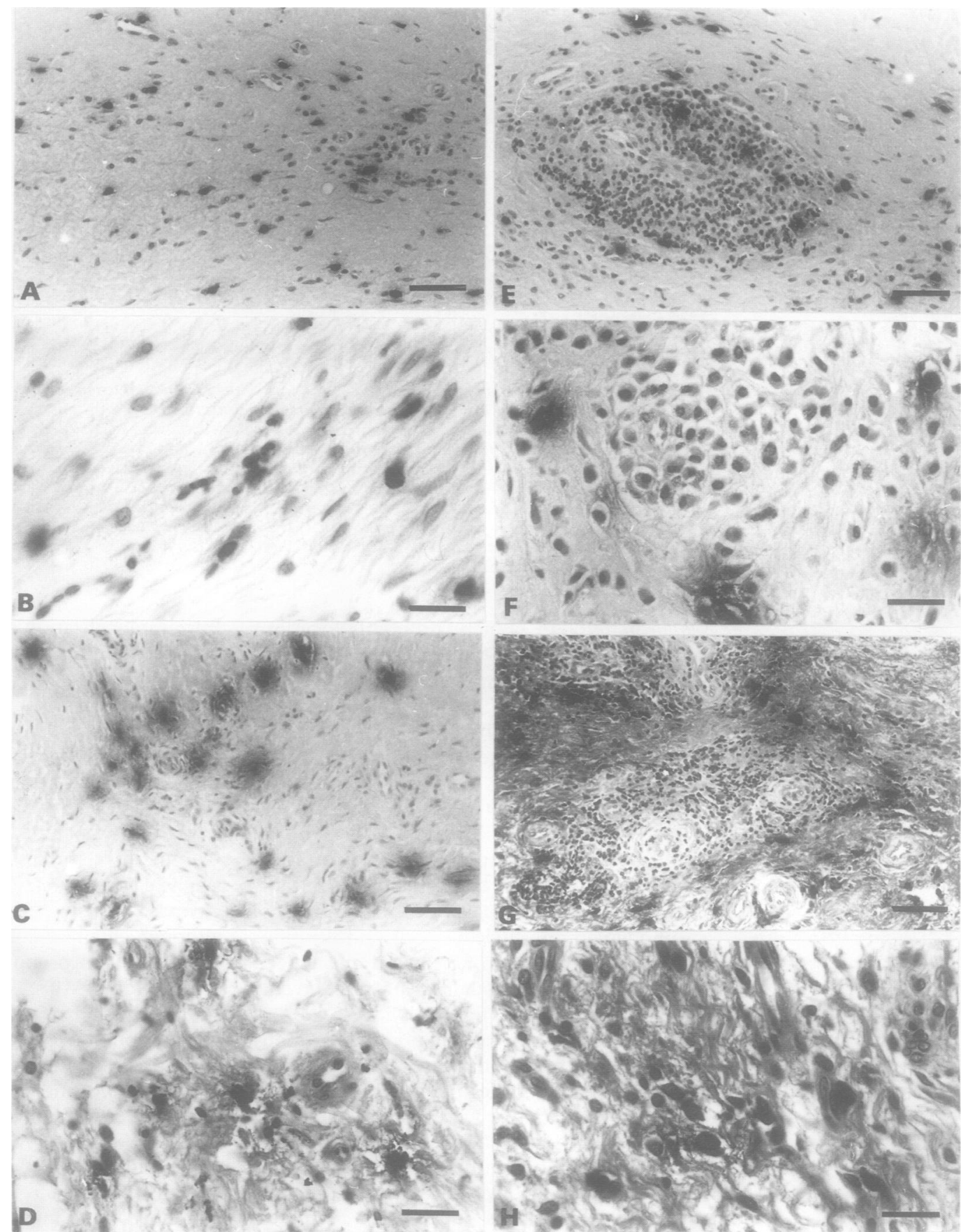

Figure 2 Immunolocalisation of mast cell (MC) tryptase in rheumatoid synovia. A: Low power photomicrograph showing the distribution of intact MCs in fibrous type rheumatoid synovium. Horizontal bar represents $60 \mu \mathrm{m} . \quad B:$ High power photomicrograph showing intact MCs in fibrous type rheumatoid synovium. Bar, $25 \mu \mathrm{m}$. (Note that in both $\boldsymbol{A}$ and $\boldsymbol{B}$ the connective tissue stroma surrounding MCs is well ordered.) $\quad \boldsymbol{C}$ : Low power photomicrograph showing intra- and extracellular staining of $M C$ tryptase associated with the stromal tissue of a cellular/fibrous specimen of rheumatoid synovium. Bar, $60 \mu \mathrm{m}$. D: High power photomicrograph of specimen $\boldsymbol{C}$, showing the association of activated degranulated MCs, visualised by darker extracellular tryptase staining, with localised tissue oedema and disruption of stromal components. Bar, $25 \mu \mathrm{m}$. E: Low power photomicrograph of MC tryptase in a cellular/fibrous specimen showing the distribution of MCs in the stromal tissue and mainly peripheral to a lymphocytic infiltration. Bar, $60 \mu \mathrm{m}$.

F: Photomicrograph of degranulated MCs around a group of plasma cells. The peripheral distribution of MCs in relation to inflammatory cell infiltrates was a common observation. Bar, $25 \mu \mathrm{m}$. G: Photomicrograph of a cellular synovial specimen showing widespread staining of tryptase throughout the tissue. Note extensive MC degranulation and stromal disruption; relatively little MC tryptase within inflammatory cell population (central location). Bar, $60 \mu \mathrm{m}$. H: High power photomicrograph of specimen $\boldsymbol{G}$, showing evidence of tissue oedema and stromal disruption associated with heavy extracellular immunostaining of MC tryptase as visualised by the dark appearance of micrographs $\boldsymbol{G}$ and $\boldsymbol{H}$. Bar, $25 \mu \mathrm{m}$. 
in tissue histology, with cellular heterogeneity at sites of cartilage erosion and variable ratios of fibrous and cellular components even within samples derived from the same joint. ${ }^{121}$ It was therefore not surprising that a variety of $\mathrm{MC}$ observations became evident, not least the realisation that MCs seldom have a uniform tissue distribution, thereby indicating difficulties in relating synovial MC numbers to clinical disease activity. Indeed, the data presented in the table indicate that proportionally more MCs were present in fibrous, more quiescent synovial specimens than in those with active inflammatory cell infiltrations. Although MCs were demonstrated in every specimen, their increased distribution and apparent activation at cartilage-pannus junctions were evident in a significant proportion of the specimens (approximately 60\%) examined. Moreover, MC activation/degranulation in many specimens appeared to be localised to specific regions of the tissues. Since the demonstration of extracellular tryptase implies that other MC granule components such as heparin, histamine, hydrolases, and some cytokines are released concomitantly, it was to be expected that such sites would often show localised

Mast cell distribution and relative proportions in rheumatoid synovial tissues

\begin{tabular}{ll}
\hline Tissue type & $\begin{array}{l}\text { Mast cells as } \\
\% \text { of total cells }\end{array}$ \\
\hline Cellular $(\mathrm{n}=8)$ & $1 \cdot 18(0 \cdot 18)^{\star \star}$ \\
Fibrous $(\mathrm{n}=7)$ & $2 \cdot 80(0 \cdot 48)$ \\
Cellular/fibrous $(\mathrm{n}=6)$ & $2 \cdot 19(0 \cdot 67)$ \\
\hline
\end{tabular}

Values are mean $(S D) . \star \star$ Significant difference $(p<0.005)$ compared with fibrous types (Student's $t$ test); other differences not significant. oedema and damaged connective tissue elements, for example as described in figure 2 . However, the tryptase enzyme is a tetramer which loses activity upon conversion to its monomeric form via its dissociation from heparin. ${ }^{22}$ At present we are uncertain how long this inactive monomeric tryptase remains in the tissues awaiting processing and elimination; thus it is difficult to judge precisely when MC degranulation occurred in the tissue before fixation. This realisation may account for the variable extents of oedema and stromal lysis observed in association with extracellular tryptase, the former processes probably being short term sequential events following MC degranulation, as demonstrated experimentally in rat mesentery. ${ }^{23}$

In humans, two types of MC have been identified by immunohistochemical analysis. The $\mathrm{MC}_{\mathrm{T}}$ type contains only tryptase and predominates in lung and intestinal mucosal tissues, whereas the $\mathrm{MC}_{\mathrm{TC}}$ type contains tryptase, chymase, carboxypeptidase, and a cathepsin G-like protease and predominates in normal skin and intestinal submucosa. ${ }^{9}$ All the MC enzymes form macromolecular complexes with heparin proteoglycan of the secretory granules, the proteinases becoming released upon extracellular extrusion and subsequent dissolution of the granule structure. ${ }^{79}$ This study has shown that both MC phenotypes are present in rheumatoid synovia, with an $\mathrm{MC}_{\mathrm{T}}: \mathrm{MC}_{\mathrm{TC}}$ ratio of approximately $8: 1$. At present, the biological functions of the MC proteinases remain uncertain, as both tryptase and chymase have very restricted substrate specificities, ${ }^{79}$ but detailed studies of their actions against connective tissue components

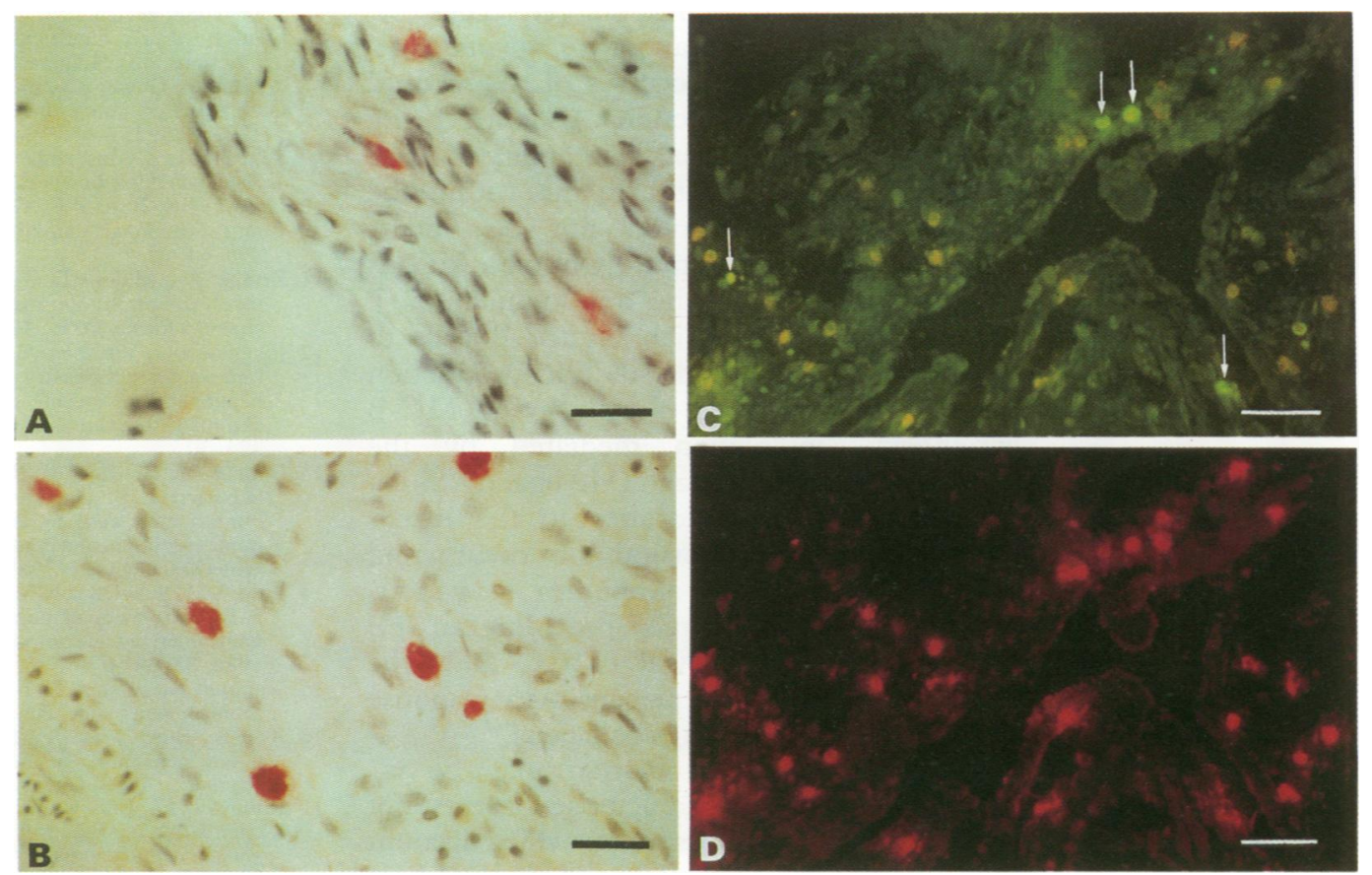

Figure 3 Immunolocalisation of mast cell (MC) chymase in the rheumatoid lesion and dual localisation of MC chymase and tryptase in rheumatoid synovial tissue. A: Photomicrograph showing synovial MCs containing chymase at the cartilage-pannus junction. Horizontal bar represents $25 \mu \mathrm{m}$. B: Photomicrograph showing the distribution of MCs containing chymase within rheumatoid synovial tissue. Bar, $25 \mu \mathrm{m}$. C: Photomicrograph showing immunolocalisation of MC chymase fluorescein isothiocyanate (FITC)-green, arrows) in rheumatoid synovial tissue. (The dull orange cells are not FITC-positive, but reflect background staining from the Fast red conjugate.) Bar, $35 \mu m$. D: Same field as $C$ showing immunolocalisation of $M C$ tryptase using Fast red immunofluorescence. Note the numbers of $M C$ s positive for tryptase alone, and that four MCs in this field contain both tryptase and chymase (arrows in C). Bar, $35 \mu \mathrm{m}$. 
have yet to be undertaken. However, both MC enzymes have been implicated in the activation of precursor forms of the matrix metalloproteinases. Tryptase directly activates prostromelysin, ${ }^{24} 25$ whereas chymase activates both prostromelysin and procollagenase via proteolytic cleavage of the propeptides..$^{25} \mathrm{As}$ both collagenase and stromelysin have been immunologically identified at sites of cartilage erosion, ${ }^{21}{ }^{27}$ and in microenvironmental sites of rheumatoid synovial tissues, ${ }^{28}{ }^{29}$ their codistribution with $\mathrm{MC}$ proteinases in some specimens represents an important observation (L Tetlow, unpublished data) of immediate relevance to the mechanisms of matrix degradation.

Histamine is a major component of $\mathrm{MC}$ granules and is one of several mediators responsible for inducing changes in vasopermeability and oedema. ${ }^{30} 31$ Histamine receptors are expressed by most cell types of the rheumatoid lesion, including lymphocytes, endothelial cells, fibroblasts, and chondrocytes. ${ }^{31}{ }^{32}$ Thus histamine release associated with MC activation is likely to induce a variety of behavioural responses by specific synoviocytes, in addition to disruption of the stromal matrix as a result of localised oedema.

Soluble MC products have been shown to stimulate collagenase and prostaglandin $\mathrm{E}$ production by both synovial fibroblasts and chondrocytes in vitro, ${ }^{33} 34$ and to stimulate interleukin-1 (IL-1) production by monocytemacrophages. ${ }^{35}$ These responses might well be explained by recent reports that human MCs express a range of multifunctional cytokines including IL-4, IL-5, IL-6 ${ }^{36}$ and especially tumour necrosis factor $\alpha(\mathrm{TNF} \alpha)^{10}{ }^{37}$ - a factor known to stimulate metalloproteinase and IL-1 expression by specific target cells. ${ }^{38}{ }^{39}$ Moreover, as TNF $\alpha$ may play a 'pivotal role' in the inflammatory processes of rheumatoid arthritis, ${ }^{39}$ its production usually being assigned to macrophages, ${ }^{40}$ the ability of MCs to generate this potent cytokine within the rheumatoid lesion should not be underestimated. IL-4 production by human MCs is reported to influence the development of $\mathrm{T}$ helper type 2 cells which induce B cells to synthesise $\operatorname{IgE}$ antibodies. ${ }^{9}$ IgE production might also be induced directly by an MC-B lymphocyte interaction mediated by the expression of a functional CD40 ligand. ${ }^{41}$ Such interactions are of relevance to the recent reports that a proportion of rheumatoid patients produce IgE antibodies to various cartilage collagens, thereby providing an IgE sensitisation of synovial MCs and the possibility of a type I hypersensitivity response upon exposure to cartilage collagens. ${ }^{42}$

MC activation/degranulation may be induced by several well characterised factors, not only by IgE mediated responses which account for allergic responses and immediate hypersensitivity reactions. Such MC stimulatory factors include soluble components released by a variety of cell types including $T$ lymphocytes, monocyte-macrophages, neutrophils, eosinophils, and platelets, in addition to some neuropeptides such as substance P. ${ }^{5}$
Thus the observations of MC degranulation demonstrated in this study may have several explanations, but the consequence of such activation is likely to affect profoundly the inflammatory lesion. The release of potent MC mediators such as histamine, proteinases, cytokines, and leukotrienes is likely to perpetuate chronic inflammation, exacerbate cartilage degradation, and stimulate the recruitment and activities of neighbouring cells. This histological study of the rheumatoid lesion demonstrates the extent of MC distributions, their activation, and local stromal changes associated with MC degranulation. Such observations suggest that the MC might prove to be a suitable target for the pharmacological interruption of a sequence of events which, by all accounts, seem detrimental to joint repair.

This work was supported by research grant WO147 from the Arthritis and Rheumatism Council, UK and, in part, by the Oliver Bird Fund for Research into Rheumatism. We thank consultant orthopaedic surgeons T Dunningham (Tameside Hospital, Manchester), M Morris (Devonshire Royal Hospital, Buxton) and $\mathrm{H}$ Bertfield (Wythenshawe Hospital, Manchester) for the supply of rheumatoid tissues; and Dr M Bromley for MC for the supply of rheumatoid tissues
quantification in svnovial tissue.

1 Bromley M, Woolley D E. Histopathology of the rheumatoid lesion. Identification of cell types at sites of cartilage erosion. Arthritis Rheum 1984; 27: 857-63.

2 Crisp A J, Chapman C M, Kirkham S E, Schiller A L, Kran $\mathrm{S} . \mathrm{M}$. Articular mastocytosis in rheumatoid arthritis Arthritis Rheum 1984; 27: 845-51

3 Godfrey H P, Ilardi C, Engber W, Graziano F .M Quantitation of human synovial mast cells in rheumatoid arthritis and other rheumatic diseases. Arthritis Rheum 1984; 27 : $852-6$.

4 Malone D G, Irani A-M, Schwartz L B, Barret K E Metcalfe D D. Mast cell numbers and histamine levels in synovial fluids from patients with diverse arthritides. Arnovial fluids from patients with

5 Gruber B, Poznansky M, Boss E, Partin J, Gorevic P, Kaplan A P. Characterization and functional studies of rheumatoid synovial mast cells. Arthritis Rheum 1986;29: $944-55$.

6 Bromley M, Fisher W D, Woolley D E. Mast cells at sites of cartilage erosion in the rheumatoid joint. Ann Rhewn Dis $1984 ;$ 43: 76-9.

7 Church M K, Caulfield J P. Mast cell and basophil functions. In: Holgate S T, Church M K, eds. Allergv: London: Gower Medical Publishing, 1993; 5.1-12.

8 Galli S J. New concepts about the mast cell. N Engl 7 . Med 1993; 328: 257-65

9 Schwartz L B. Mast cells: function and contents. Curr Opin Immunol 1994; 6: 91-7.

10 Gordon J R, Burd P R, Galli S J. Mast cells as a source of multifunctional cytokines. Immunol Today 1990; 11: 458-64.

11 Bridges A J, Malone D G, Jicinsky J, et al. Human mast cell involvement in rheumatoid arthritis and osteoarthritis. Arthritis Rheum 1991; 34: 1116-24

12 Johansson $\mathrm{O}$, Virtanen M, Hilliges M, Yang Q. Histamine immunohistochemistry is superior to the conventional heparin-based routine staining methodology for investigations of human skin mast cells. Histochem f 1994; 26: $424-30$.

13 Irani A-M, Bradford T R, Kepley C L, Schechter X . M, Schwartz L B. Detection of $\mathrm{MC}_{\mathrm{T}}$ and $M \mathrm{C}_{\mathrm{T}}$. types of Schwartz L B. Detection of $\mathrm{MC}_{\mathrm{T}}$ and $\mathrm{MC}_{\mathrm{TC}}$ types of monoclonal anti-tryptase and anti-chymase antibodies. $\mathcal{f}$ monoclonal anti-tryptase and anti-chymas

4 Irani A M, Schechter N M, Craig S S, DeBlois G, Schwartz $\mathrm{L}$ B. Two types of human mast cells that have distinct neutral protease compositions. Proc Natl Acad Si USA 1986; 83: 4464-8.

5 Weidner N, Austen K F. Heterogeneity of mast cells at multiple body sites. Path Res Pract 1993; 189: 156-62.

16 Kopicky-Burd J A, Kagey-Sobotka A, Peters SP, et al. Characterization of human synovial mast cells. $f$ Rheumatol 1988; 15: 1326-33.

17 Robinson G, Ellis I O, MacLennan K A. Immunocytochemistry. In: Bancroft J D, Stevens A, eds. Theory and practice of histological techniques. Edinburgh: Churchill practice of histological teche

18 Baggiolini $\mathrm{M}$, Horisberger $\mathrm{U}$, Martin $\mathrm{U}$. Phagocytosis of mast cell granules by mononuclear phagocytes, of mast cell granules by mononuclear phagocytes, neutrophils and eosinophils during anaph

19 Subba-Rao P V, Friedman M M. Atkins F M, Metcalfe D D. Phagocytosis of mast cell granules by cultured
D. D D. Phagocytosis of mast cell gran

20 Castor C E. The microscopic structure of human synovial tissue Arthritis Rheum 1960; 3: 140-51. 
21 Woolley D E. Cellular mechanisms of cartilage destruction. In: Henderson B, Edwards J, Pettipher R, eds. Mechanisms and models in rheumatoid arthritis. London: Academic Press 1995; 115-32.

22 Schwartz L B, Bradford T R. Regulation of tryptase from human lung mast cells by heparin, stabilization of the active tetramer. $₹$ Biol Chem 1986; 261: 7372-9.

23 Norrby K, Enestrom $S$. Cellular and extracellular changes following mast-cell secretion in avascular rat mesentery. Cell Tissue Res 1984; 235: 339-45.

24 Gruber B L, Marchese M J, Suzuki K, et al. Synovial procollagenase activation by human mast cell tryptase dependence upon matrix metalloproteinase 3 activation. fClin Invest 1989; 84: 1657-62.

25 Lees M, Taylor D J, Woolley D E. Mast cell proteinases activate precursor forms of collagenase and stromelysin, but not of gelatinase A and B. Eur $\mathcal{f}$ Biochem 1994; 223: but not

26 Saarinen J, Kalkinen N, Welgus H G, Kovaren P T. Activation of human interstitial procollagenase through direct cleavage of the leu 83 -thr 84 bond by mast cell chymase. 7 Biol Chem 1994; 269: $18134-40$.

27 Woolley D E, Crossley M J, Evanson J M. Collagenase at sites of cartilage erosion in the rheumatoid joint. Arthritis Rheum 1977; 20: 1231-9.

28 Tetlow L C, Lees M, Ogata Y, Nagase $H$, Woolley D E. Differential expression of gelatinase $B(M M P-9)$ and stromelysin-1 (MMP-3) by theumatoid synovial cells in stromelysin-1 (MMP-3) by theumatoid syno
vitro and vivo. Rheumatol Int 1993; 13: 53-9.

29 Okada Y, Takeuchi N, Tomita K, Nakanishi I, Nagase H. Immunolocalisation of matrix metalloproteinase 3 (stromelysin) in rheumatoid synovioblasts (B cells): correlation with rheumatoid arthritis. Ann Rheum Dis 1989; 48: 645-53.

30 Malone D G, Vikingsson A, Seebruch J S, Verbsky J W, Dolan $P$ W. In vivo effects of nonsteroidal antiinflammatory drugs on rat skin and synovial mast cell-induced vasopermeability. Arthritis Rheum 1991; 4: 164-70.

31 White M, Kaliner M A. Histamine. In: Gallin J I, Goldstein I M, Snyderman R, eds. Inflammation; basic principles and clinical correlates. New York: Raven Press, 1988; 169-93.
32 Taylor D J, Yoffe J R, Brown D M, Woolley D E. Histamine stimulates prostaglandin $\mathrm{E}$ production by rheumatoid synovial cells and human articular chondrocytes in culture. Arthritis Rheum 1986; 29: 160-5.

33 Yoffe J R, Taylor D J, Woolley D E. Mast cell products stimulate collagenase and prostaglandin $\mathrm{E}$ production by cultures of rheumatoid synovial cells. Biochem Biophys Res Comm 1984; 122: 270-6.

34 Woolley D E, Yoffe J R, Evanson J M. Mast cells and matrix degradation in the rheumatoid joint. In: Tschesche $\mathrm{H}$, ed. Proteinases in inflammation and tumour invasion. Berlin, New York: Walter de Gruyter \& Co, 1986; 61-76.

35 Yoffe J R, Taylor D J, Woolley D E. Mast cell products and heparin stimulate the production of mononuclear-cell heparin stimulate the production of mononuclear-cell Bactor by cultured hum

36 Bradding $\mathrm{P}$, Feather I $\mathrm{H}$, Wilson $\mathrm{S}$, et al. The mast cell as a source of IL-4, IL-5 and IL-6 in human allergic mucosal inflammation. F Immunol 1993; 151: 3853-65.

37 Walsh L J, Trinchieri G, Waldorf H A, Whitaker D, Murphy G. Human dermal mast cells contain and release tumour necrosis factor $\alpha$, which induces endothelial leukocyte adhesion molecule 1. Proc Natl Acad Sci USA 1991; 88: $4220-4$.

38 Dayer J M, Beutler B, Cerami A. Cachetin/tumour necrosis factor stimulates collagenase and prostaglandin $E_{2}$ production by human synovial cells and dermal production by human synovial cells
fibroblasts. $\mathcal{F}$ Exp Med 1985; 162: 21 $63-8$.

39 Brennan F M, Maini R N, Feldmann M. TNF- $\alpha-a$ pivotal role in rheumatoid arthritis? Br $\mathcal{F}$ Rheumatol 1992; 31: 293-8.

40 Chu C Q, Field M, Feldmann M, Maini R N. Localisation of tumour necrosis factor $\alpha$ in synovial tissue and at the cartilage pannus junction in patients with rheumatoid arthritis. Arthritis Rheum 1991; 34: 1125-32.

41 Gauchat J F, Henchoz S, Mazzei G, et al. Induction of human IgE synthesis in $B$ cells by mast cells and basophils. Nature 1993; 365: 340-3.

42 Cooper A L Snowden N, Woolley D E. IgE antibodies specific for cartilage collagens type II, IX and XI in specific for cartilage collagens type II, $\mathrm{X}$ and $\mathrm{XI}$ in
rheumatic diseases. Scand $\mathcal{F}$ Rheumatol 1993; 22: 207-14. 